\section{Understanding the Value of Travel: Study Abroad Progam in Barcelona}

Camilo Cerro

American University of Sharjah

\section{ABSTRACT:}

As most design pedagogies focus on typological, tectonic, compositional, and technological studies there is an experiential teaching component that has the potential to bring them all together having also the strongest repercussion on the development of an ethical, independent mind; that is travel. The capacity to function with other cultures, learn independence and adaptability, experience a building by walking into it instead of looking at photos, and designing for a different set of rules other than the ones the students is accustomed to, are all some of the outcomes of participating in a study abroad program. Understanding the value of travel, our college started a study abroad program two years ago. Currently preparing for our third semester in Barcelona, we have been assessing what has worked and what has not so we can adapt and evolve to keep the program fresh and relevant. This paper will cover our pedagogy and process, the type of classes we taught and the reasons behind them but more than anything, the way it has changed the participating students when compared to those who have not participated in a program of this type. The semester was divided into four courses: ARC394-Places and Culture, was designed to function as a walking tour of the city of Barcelona, where the students learned on the go by visiting sites following a chronological history of the city that took place throughout the semester. ARC494-Contemporary Architecture Practice, took place in both the classroom and by visiting contemporary architecture sites. The course was taught by EMBT (Enric Miralles and Benedetta Tagliabue) as an opportunity for the students to learn the design thinking and process behind the main project of a working architectural firm as they take an idea from sketch to construction. ARC581-Contemporary Spanish Architecture, offered the student the opportunity to visit: Seville, Cordoba, Granada, Bilbao, Madrid, Figueres and Olot on walking tours covering the history of these locations from an architectural and design perspective from antiquity to modernity. And finally, ARC501-401, a vertical design studio where the student was able to bring all the classes together to design a project in the city of Barcelona, putting to the test, how their experiences influenced their designs. All of these courses where designed to work together creating an interdependent system that allowed the participants to learn through experiencing architecture and design, while being able to implement that newly learned design knowledge into site and cultural specific design projects.

Keywords: Study Abroad, Barcelona, pedagogy, independence, adaptability.

\section{INTRODUCTION-THE HUNCH:}

While thinking about this paper, I realized that I approached the theme of the conference from the belief that the hunch in my case mainly refers to personal experience. I have been fortunate to travel a lot in my lifetime ( 67 countries). And I believe, that the basis of my design-ethic approach comes from experiences that happened while traveling. Under this frame of mind, it was clear to me that giving students the opportunity of extended travel was incredibly necessary for any academic institution. Even though, at the beginning, I started 
taking students to one week trips during spring break, I quickly realized that for them to take full advantage of the experience, the trips would have to be longer and stay focused on one location instead of spending three days here and there. In 2014, I took students for a month to Cambodia, and it was here that I started understanding the real potential of displacement. To place students in a different culture than their own for an extended period of time forced them to adapt in the same way I still do every time I travel myself. This adaptability, compelled them to understand their surroundings to function, and by doing so, as they understood how the new place functioned, they were able to start designing for the needs of that community. Sometimes naively, romanticized and full of preconceptions but at all times experiential in nature. I thought with the right program, an extended study abroad course had the potential to teach the student about the social aspect of design, by engaging in field work; walking streets, engaging with the community, and people watching. This first experience, opened the door to what would become the American University of Sharjah's study abroad program.

\section{PROGRAM LOGISTICS:}

The program evolved from a shorter (one month long) study abroad summer course, to a full semester term that presented a different set of logistical challenges. Most of which dealt with having to keep the sequence of courses undisturbed so that the participants could graduate with the rest of their class. The program also had to conform to aspects of our NAAB accreditation and it needed to be approved by the ministry of education in the UAE. To deal with all the bureaucratic aspects of the study abroad program the College of Architecture, Art and Design established a committee to deal with all the logistics. The most problematic aspect of the process was related to getting four month long visas for students with Middle Eastern passports at a time when Europe has been experiencing immigration issues. An educational institution in the host country needs to take responsibility for the students, this is where the Enric Miralles Foundation came in, not only providing letters inviting the students but also accommodations and classroom space for our program. In the end, the students needed to present a letter from the American University of Sharjah, one from EMBT and a copy of their parents bank statements to prove that they were not interested in immigrating to Europe. The program was designed around four courses (15 credits): Two taught by adjunct professors based in Barcelona and the other two by a professor from the American University of Sharjah relocated to Barcelona for the extent of the term. The courses are: ARC-581: Contemporary Spanish Architecture (3 credits), ARC-494: Contemporary Architecture Practice (3 credits), ARC-394: Places And Culture ( 3 credits) and ARC-401/501: Studio (6 credits) will be explained later in the paper. Once the bureaucracy was dealt with and a program established on paper, it was time to work on the methodology of the program.

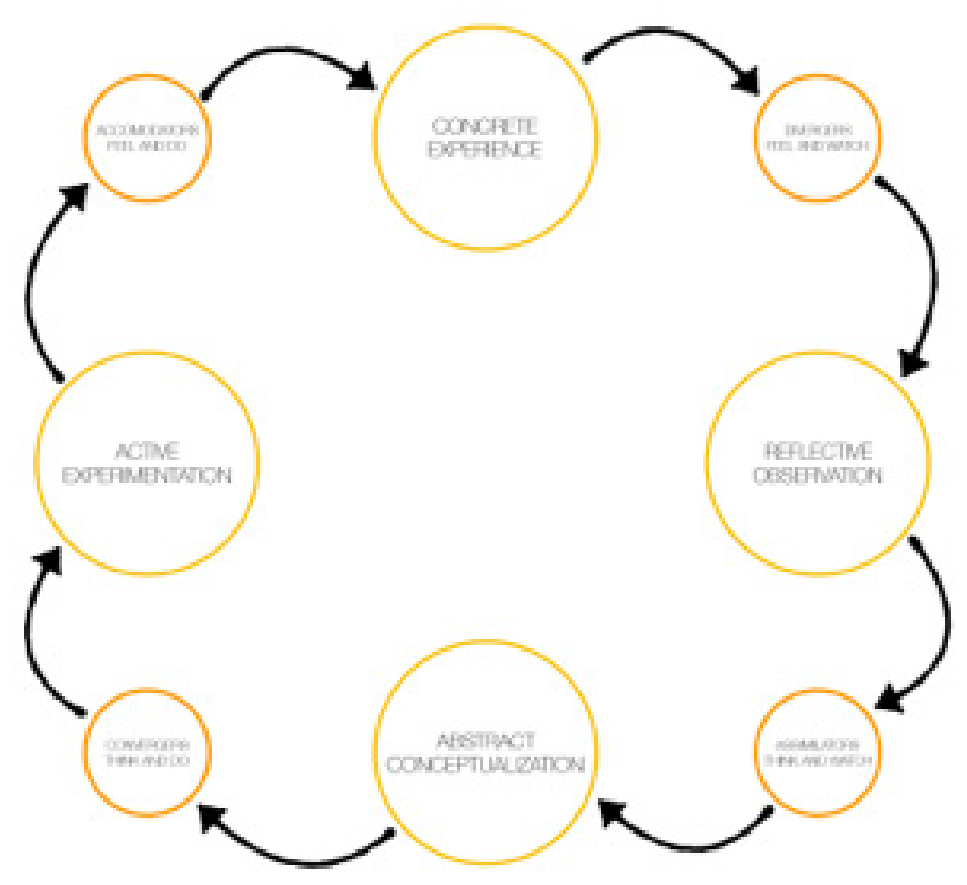

Figure 1: David Kolb's experiential learning style theory is typically represented by a four-stage learning cycle. 


\section{METHODOLOGY: THE EXPERIENTIAL LEARNING CYCLE}

The study abroad program has been structured to engage learning through interacting with specific experiences based on the learning cycle proposed by David A. Kolb in his book; Experiential Learning: Experience as the Source of Learning and Development [1]. In it, Kolb views learning as an integrated process were each stage is mutually supportive of and feeding into the next one. For him, learning is the process whereby knowledge is created through the transformation of experience. It is possible to enter the cycle at any stage and follow it through its logical sequence (figure 1) in a loop. Effective learning is seen when the student progresses through this cycle of four stages: it starts with having a concrete experience (a new experience or situation is encountered, or a reinterpretation of existing experiences) followed by, observation of and reflection (of particular importance are any inconsistencies between experience and understanding) on that experience which leads to, the formation of abstract concepts and generalizations (reflection gives rise to a new idea, or a modification of an existing abstract concept. The student has learned from their experience) which are then, used to test hypothesis in future situations (the student applies their idea(s) to the world around them to see what happens), resulting in new experiences. Based on this learning cycle, Kolb sets out four distinct learning styles; The accommodators (feel and do), the divergers (feel and watch), the assimilators (think and watch) and the convergers (think and do), all of which are explained below:

Accommodators: People with accommodating learning style are hands-on, and rely on intuition rather than logic. These people use other peoples analyses, and prefer to take a practical, experiential approach. They are attracted to new challenges and experiences, and to carrying out plans. They commonly act on gut instinct rather than logical analysis. This learning style is prevalent within the general population.

Divergers: People with a diverging learning are able to look at things from different perspectives. They are sensitive. They prefer to watch rather than do, tending to gather information and use imagination to solve problems. They are best at viewing concrete situations from several different viewpoints. People with a diverging learning style have broad cultural interests and like to gather information.

Assimilators: people with assimilating learning preference have a concise, logical approach. Ideas and concepts are more important than people. These people require good clear explanation rather than a practical opportunity. They excel at understanding wideranging information and organizing it in a clear, logical format. People with an assimilating learning style are less focused on people and more interested in ideas and abstract concepts. People with this style are more attracted to logically sound theories than approaches based on practical value.

Convergers: People with a converging learning style can solve problems and will use their learning to find solutions to practical issues. They prefer technical tasks, and are less concerned with people and interpersonal aspects. People with a converging learning style are best at finding practical uses for ideas and theories. They can solve problems and make decisions by finding solutions to questions and problems.

With these in mind the activities in the program have been designed to engage in ways that offer each learner the chance to participate in the manner that suits them best. One of the easiest ways to assure that a student is confronted with a different learning style than their own is by working in groups but also, so that they are challenged to deal not only with their style but the others, the students are not allowed to keep the same groups through the other classes. The groups are set to have two different styles per group forcing the students to broaden their learning parameters to adapt to their partners. From this perspective, you will find following the ways this methodology will be applied to each of the classes.

\section{ARC-581:CONTEMPORARY SPANISH ARCHITECTURE}

This course was designed to examine the role and application of research methodology and critical thinking in the work of leading practitioners and academics. It investigates a current topic in contemporary discourse to be chosen by the students, focusing on how to; articulate and apply theory and research in architectural production. The course foregrounds the history of ideas that frame and influence contemporary trends in the discipline. Focusing on applying critical thinking skills to the analysis and production of architecture as a mode of inquiry. To achieve this, the course was designed to take place on the streets of Barcelona where the students will implement the experiential learning cycle as they engage the city during every class.

\section{ARC-394: PLACES AND CULTURE}

This is probably the course that is best suited to dealing with the learning activities (feeling \& doing, thinking \& watching, thinking and doing and feeling and watching) presented by Kolb. In this course the students have the opportunity to travel to different parts of Spain for extended weekends in which we visit (Madrid, Bilbao, San Sebastian, Cordoba, Granada, Seville, Valencia and Figueres) different cities. The tour forces the student to be independent by having to deal with their accommodation, nourishment and travel management. Classes start at 10:00am at a given location, to which the students need to arrive by adapting to the new place and interacting with it. The course is basically a walking tour of each of the given city's; museums, architectural sites, parks, historical buildings, etc. Through this walking tour, we as a group, stop to talk about what we see, specifically about the thinking process behind some of the architectural moves that we see around us defining the urban fabric. Information that will manifest in their course assignment and their studio projects. The assignment for this course is a video diary ( $3 \mathrm{~min}$. in duration) that the student puts together and edits in groups of two. The video needs to document something that attracted their attention through each of the trips, providing a medium for the implementation of the learning activities. 


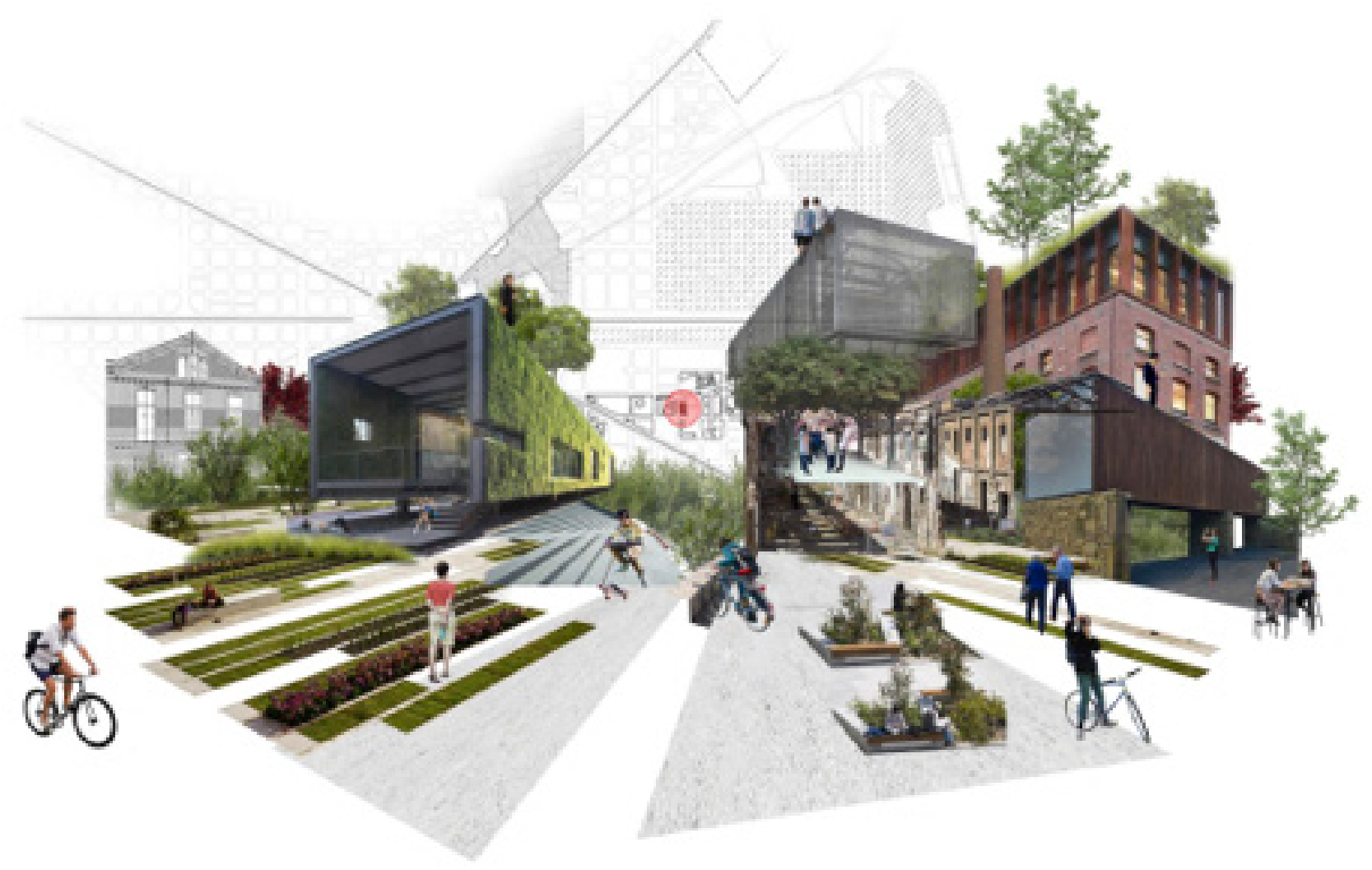

Figure 2: Student work by Yasmine Fahmy \& Abdukarim Umarov

\section{ARC-494: CONTEMPORARY ARCHITECTURE PRACTICE}

In this course, which is taught by EMBT (Enric Miralles and Benedetta Tagliabue), the students have an inside look at the design process from beginning to end by looking at the work of this award winning firm. Throughout the course the students visit the actual sites of the built work and receive explanations of the design processes from the designers themselves. Through this process, the students get to implement the learning activities (feeling \& doing, thinking \& watching, thinking and doing and feeling and watching) directly, which culminate in assignments designed to manifest the learned material; like through EMBT's emblematic collage technique (figure 2) which the students learn as part of the course.

\section{ARC-401/501: STUDIO}

The studio becomes a lab for doing (designing) which is the basic premise of the design process. Through it, the student uses their project to implement the experiences learned in the other courses closing a loop that in essence, generates new experiences. The project's conceptual design gets informed by elements that the students implement from their other courses into a translation of these previous experiences that take the form of design ideas that ground the design projects in socio-cultural specificity. In the end, finishing the learning cycle with a programmatic result informed by their study abroad experience.

\section{CHOOSING THE RIGHT PLACE: WHY BARCELONA?}

Obviously it takes a lot of time looking for potential cities to choose the right one for a study abroad program, because there are a lot of factors to consider that need to come together for the program to manifest. Following, I will present a series of factors that help me structure this type of program, understanding as you will see ahead, that this presentation worked for our own specificities and will be different for other programs. The first factor we considered was finding a small city. Why small? Well, mainly because the program is trying to make the student experience the place both inside and outside the classroom. For this to be the case, a walkable small city that allows the student to get lost and find her/his way again is less overwhelming than a megalopolis. A small city provides, after some time, a level of intimacy and control, especially if they can walk or bike around. The city also had to be culturally rich and full of activities to keep the student engaged and entertained. There will be a lot of free time outside of classes, and it is important that the students become independent, and make plans together. For this reason, the city should have lots of museums, architectural and historical sites, parks, cultural festivals 


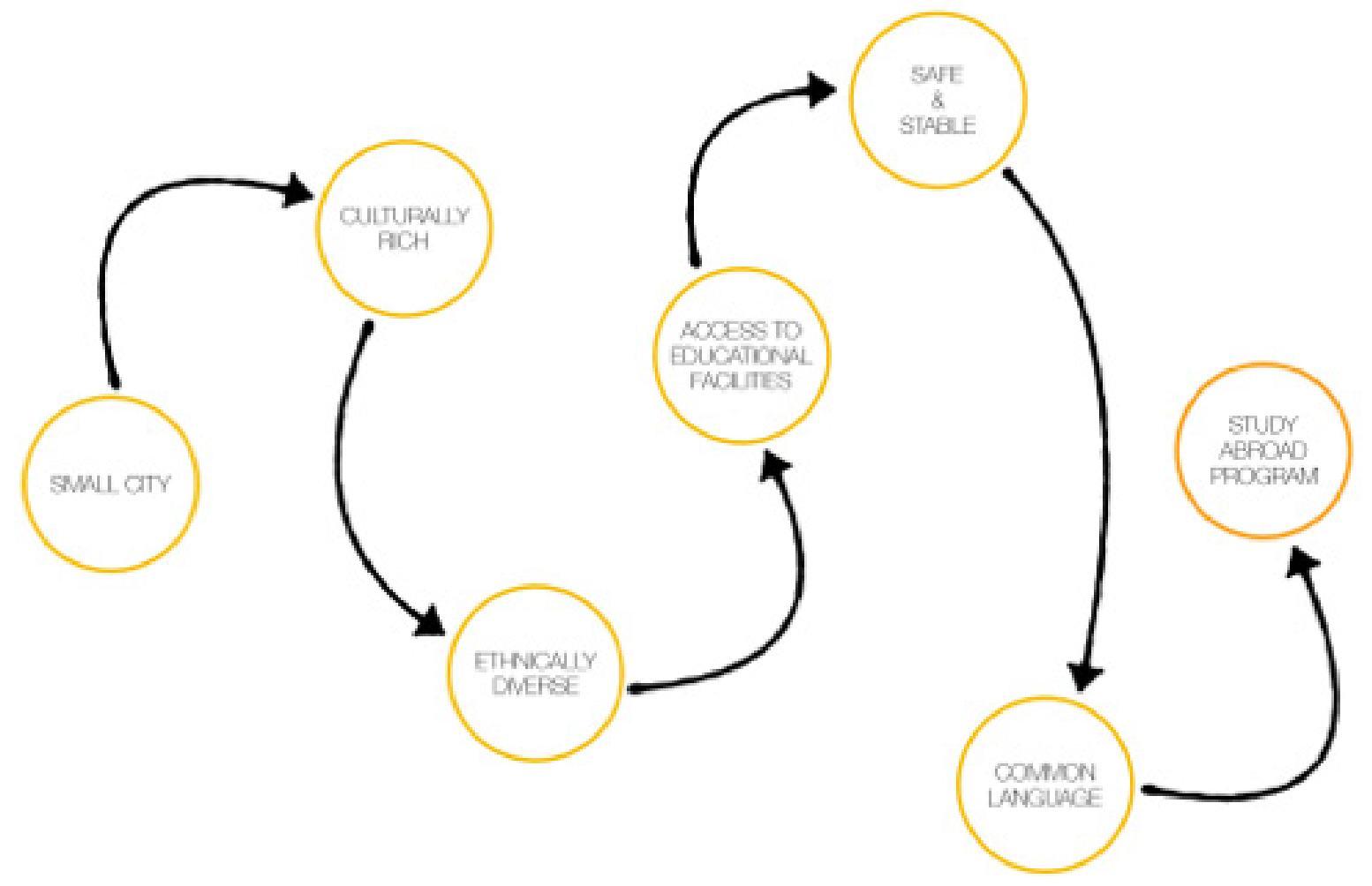

Figure 3: Choosing the right city.

and concerts. The city should also be ethnically diverse, this point is especially important for our student population which is very internationally diverse (80 different countries). A city with multiple ethnicity has a history of tolerance making life for our students a lot more peaceful. We want a place where the students will be accepted by their host community. Where this community is used to having people visit and which is prepared and welcoming to them. The city also needs to have access to educational facilities to allow for their education to take place. The American University of Sharjah has some of the best labs in Asia, the student participating in the program knows that in this sense, any place we chose as our location will be deficient on this capacity.

This is why the program has been designed to be very low maintenance. The students will design in a paperless studio that only requires a room and a projector, they will bring their own computers. But the place needs to be comfortable and safe, so that the students can leave their stuff set up without fearing for it. And most importantly, the place needs to be associated with an educational venue capable of writing invitation letters for the students to be able to get extended academic visas. Only universities and some foundations are capable of emitting this document. Another important point is safety. Crime is a problem in a lot of places and it is something to be avoided if possible. We have pre-trip classes where we cover amongst other things all the possible petty crime situations in the shape they take in the places we are visiting, so the students are aware of the flavor of situations that need to be avoided. This point is not always avoidable, on our first year doing the program in Barcelona, there was a terrorist attack in the Rambla and during most of the semester, the students lived the Catalan attempt at independence. Barcelona is also the pickpocketing capital of the world. We knew and prepared for this last point. The others required good management and adaptability. Finally, the city needs to have a common language, it is important that the student can communicate, so the city has to have be able to function with some level of English. All our students speak perfect English besides Arabic, Persian, Hindi, Urdu and other local languages, but the American University of Sharjah is an English speaking program. So, the city we stay in has to be English savvy, to allow for the students to develop some level of independence. We looked at many places with the potential to fulfill our needs, and Barcelona was chosen not because if filled perfectly our requirements but because it did so to an acceptable level allowing the student to be independent and learn as much from the city by them self as they will from the program. For them, coming from a city that did not exist fifty years ago (Dubai), walking the streets of Barcelona is like going back in time, every street is an adventure to be experienced, the food is exotic (even though that they will end up in McDonalds more times than I would like), the museums diverse, all of it at a scale they have never experienced previously. That is what I remember from the first time I backpacked 
through Barcelona and that is what I see them experiencing today, with the difference that all of it becomes an Instagram moment.

\section{SUSTAINABLE DEVELOPMENT GOALS:}

As a side note, the program for this term revolves around present issues of sustainability and global warming for which we are using the United Nations sustainable development goals as the ethical basis for all the work produced this semester. According to the United Nations, the Sustainable Development Goals are the blueprint to achieve a better and more sustainable future for all. They address the global challenges we face, including those related to poverty, inequality, climate, environmental degradation, prosperity, and peace and justice [2]. With this in mind, all the courses in the program will touch on different aspects of sustainable design with the goal of implementing as many of the goals in the work produced in studio. The aim is to develop work that produces a systemic interdependence that combines design with social, economic and cultural factors while approaching this task from a sustainable perspective.

\section{CONCLUSION:}

The creation of Study Abroad Programs entails a lot of work, much more than a typical semester back in your home institution, and it has very little value in terms of your academic status giving you little time for your personal academic research. I think it is important to understand this because coordinating a program like this is by no means a vacation. You'd better be a good manager, because in addition to your workload, you will have to do the work normally done by the staff of your institution, especially dealing with the finances of the program. You should have another reason for participating on a program like this, one that compensates for the hardship that it entails. Having said that, it provides for a very controlled environment where to implement a design methodology with parameters that interest both the faculty as well as the student. In the case of our program, the methodology covers two overall ideas; The first deals with how to make the students retain and learn more from the experience they take part in. The second deals with how to implement the first into a design program that deals with sustainability related issues. The work coming out of this studio ends up being considerably more interesting than the one done by their counterparts back in the UAE. I attribute this to the overall experience of a study abroad program and the interdependent academic structure we have designed for it. The work ends up with; social components, an understanding of site specificity, strong pre-project field work, more importantly, an understanding that architecture is there to solve problems in a very Cedric Price (1934-2003) mentality. We find that the participants become more mature and independent designers and individuals, capable of working in groups and designing without being hand held. They will truly be displaced and with time they will adapt. Later on, once they are back home, they will remember the experience for the rest of their lives.

\section{WHAT IS NEXT?}

In September 2019 we will start the third year of the program. It will also take place in Barcelona, with the participation of eleven students (ten female and one male) from the American University of Sharjah. This term's theme will be heavily related to sustainability, following the parameters explained previously. Students will work in groups of two and will be given a macro program composed of micro elements. Students will have the freedom to define the micro-programs around the main theme from field research they will be doing all throughout the semester. This will add a strong social component to the projects that will push for a level of site specificity. The other courses will add to studio by touching on the main theme of sustainability which together with a series of lectures, project visits, research and reading will immerse the students in that subject for the extent of the study abroad term. At the same time, the four courses of the term will cater to the experiential learning cycle through its pedagogy and the experiential nature of the program. The expected outcome is a more independent, mature, and sustainability aware designer, capable of understanding the needs of the Anthropocene in view of the realities presented by global warming as they engage with their environments.

\section{ACKNOWLEDGMENTS:}

I would like to thank the American University of Sharjah and especially the administration of the College of Architecture, Art and Design for their constant support of my research and academic activities. EMBT (Enric Miralles and Benedetta Tagliabue) for hosting us and the students from CAAD (College of Architecture, Art and Design) for making of each trip a great experience.

\section{REFERENCES:}

1. Kolb, David A., Experiential Learning: Experience as the Source of Learning and Development, Pearson FT Press; 2 edition, 2014.

2. United Nations, The Millennium Development Goals Report 2012, UN, 2012. 